\title{
Non-invasive radiological investigation for oculomotor palsy
}

\author{
Evelyn Teasdale, Patrick Statham, John Straiton, Peter Macpherson
}

\begin{abstract}
An application of computed tomography (CT) is described in which multiplanar high resolution images of the terminal carotid and basilar arteries are obtained. This has been applied in a series of 32 patients with IIIrd nerve palsy in whom the underlying pathology was thought to be a posterior communicating artery aneurysm. The results of the CT were compared with conventional angiography. Seventeen aneurysms were detected in 13 patients by CT and all were confirmed by angiography. Vessels considered to be normal on $\mathrm{CT}$ were confirmed to be normal by angiography. This CT technique is a simple non invasive first line investigation for IIIrd nerve palsy with the ability to exclude or predict an aneurysm.
\end{abstract}

The majority of patients with an isolated IIIrd nerve palsy do not have a structural lesion. Nevertheless, most authors have recommended that all patients should have angiography ${ }^{1-4}$ because the clinical signs classically used to differentiate between intrinsic and extrinsic lesions of the IIIrd nerve are not wholly reliable. In practice it can be difficult to decide whether to submit such a patient to angiography to exclude the low probability of a lesion such as an aneurysm, especially if the patient is elderly and has vascular disease, and thus increased risks from angiography. ${ }^{56}$ The purpose of this study was to investigate the feasibility of using non-invasive assessment by dynamic CT scanning of the carotid and basilar vessels around the circle of Willis to avoid routine angiography.

Soni has reported that posterior communi-

Institute of

Neurological Sciences, Southern General Hospital, Glasgow E Teasdale

P Statham

J Straiton

P Macpherson

Correspondence to:

Dr E Teasdale,

Institute of Neurological

Sciences, Southern General

Hospital, 1345 Govan Road,

Glasgow G51 4TF,

United Kingdom.

Received 17 May 1989

and in revised form

Accepted 16 November 1989 greater, ${ }^{89}$ but its accuracy is reported to be poorest in the region of the terminal carotid did it separate those patients with or without haemorrhage. Studies of patients with subarachnoid haemorrhage indicate that dynamic arachnoid haemorrhage indicate that dynamic nerve palsy, the aneurysm measured $11 \mathrm{~mm}$ or more in its largest diameter. Unfortunately, because of artefact induced by the bones of the skull base. We have been unable to find a report of the use of dynamic scanning as a method of investigation of patients with IIIrd nerve palsy who have not had subarachnoid or intracerebral haemorrhage.

There were three stages in the study. First, we determined the size of an aneurysm associated with IIIrd nerve palsy in a retrospective series. Second, dynamic scanning was carried out on five patients who presented with subarachnoid haemorrhage and IIIrd nerve palsy to allow the technique to be assessed in cases likely to be positive and certain to come to angiography. Third, the dynamic CT technique was used in a prospective series of cases with isolated IIIrd nerve palsy in the absence of subarachnoid haemorrhage: each of these patients also had angiography.

\section{Patients and methods}

Retrospective review

The presence or absence of IIIrd nerve palsy was assessed in a consecutive series of 87 patients who had been shown angiographically to have a posterior communicating artery aneurysm. The angiograms were reviewed and the size of the aneurysm in patients with a IIIrd nerve palsy was determined.

\section{Dynamic CT Technique}

All scans were performed on a Philips 350 Tomoscan. Cuts of 15 to 18 axial $3 \mathrm{~mm}$ with 1.5 $\mathrm{mm}$ overlap were taken from the mid point of the pituitary fossa to above the circle of Willis with a gantry angle chosen to avoid radiation to the eye. Fifty $\mathrm{ml}$ of non-ionic contrast $(370 \mathrm{mg}$ $\mathrm{I} \%$ ) were injected intravenously just before the start of the axial slices, and a further $50 \mathrm{ml}$ were injected during image acquisition. From the timing of the dynamic scanning it was not anticipated that small intracavernous aneurysms could be separated from the enhancement of the cavernous sinus itself. The total examination time was between 20-30 minutes. The CT images were examined on an independent console in the axial, reformatted coronal, sagittal and true oblique projections to image both carotid and basilar systems in more detail. The oblique plane was frequently the most useful; on the axial slice a line was taken obliquely along the direction of the posterior communicating artery and then a true oblique was obtained by tilting the plane to follow the medial to lateral slope of the normal terminal poorest in the region of the terminal carotid 
Figure 1 (a) Composite showing the plane of the true oblique line for the oblique lateral reformation $(R)$ in the bottom right corner. A bulge (arrow) not seen on the axial cuts projects from the posterior aspect of the terminal carotid artery $(C)$.

(b) Carotid angiogram shows the bulge to be a $2 \mathrm{~mm}$ infundibulum.
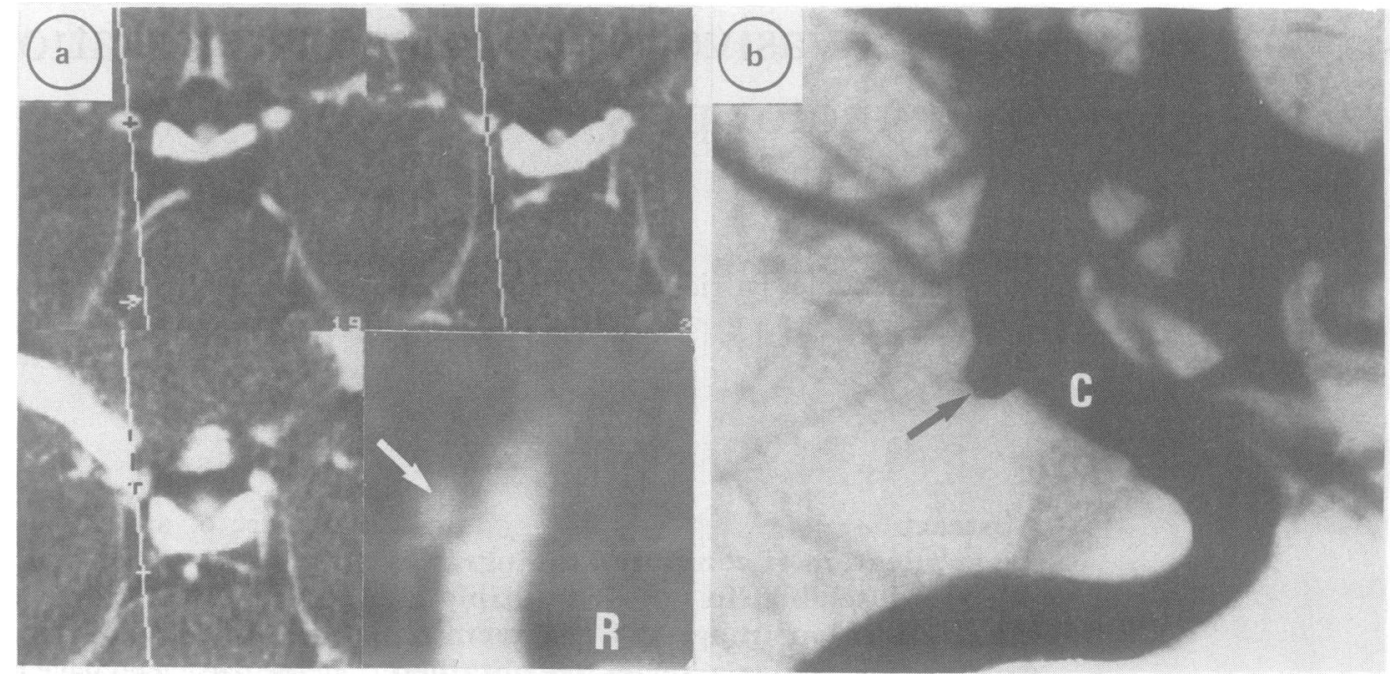

internal carotid (fig 1). This part of the examination took on average 15 minutes of the radiologists' time. All CT scans were assessed and the predictions reported to the clinicians before angiography.

\section{Angiography}

All angiograms were catheter studies performed under local anaesthesia via femoral puncture. Each of the five patients with subarachnoid haemorrhage had bilateral carotid and vertebral angiography. In the third group of 27 patients, (those with IIIrd nerve palsy and no subarachnoid haemorrhage) the ipsilateral carotid was examined in each, the contralateral carotid in 15 and the basilar system in 18 .

Table 1 Five patients with subarachnoid haemorrhage and IIIrd nerve palsy

\begin{tabular}{lll}
\hline & Dynamic CT & Angiography \\
\hline Ipsilateral carotid & 5 aneurysms & 5 aneurysms \\
pontralateral carotid & $\begin{array}{l}\text { predicted } \\
5 \text { normal }\end{array}$ & $\begin{array}{l}\text { confirmed } \\
\text { 1 normal } \\
\text { intracavernous } \\
\text { aneurysm }\end{array}$ \\
& & $\begin{array}{l}4 \text { normal } \\
\text { spasm }\end{array}$ \\
\hline
\end{tabular}

\section{Results}

Retrospective review

Of the 87 aneurysms, 15 were associated with a IIIrd nerve palsy, only two in the absence of subarachnoid haemorrhage. These two aneurysms measured $10 \mathrm{~mm}$ and $11 \mathrm{~mm}$ in their maximum diameter whereas in those with palsy and haemorrhage the average maximum diameter was $9 \mathrm{~mm}$ (range $4 \mathrm{~mm}-25 \mathrm{~mm}$ ). The size of these aneurysms indicated that they should be within the limits of resolution by dynamic CT.

\section{Patients with subarachnoid haemorrhage and}

IIIrd nerve palsy (table 1)

CT identified an ipsilateral aneurysm in each of the five patients, the contralateral carotid was normal in five and the basilar artery in four. One basilar artery showed considerable irregularity. Angiography confirmed all these findings and showed that the irregularity of the one abnormal basilar artery was due to spasm. CT did not show and would not have been expected to show, the small intracavernous aneurysm shown by angiography in one case.

\section{Twenty seven patients with IIIrd nerve palsy} and without subarachnoid haemorrhage

There were 18 females and 19 males with an average age of 47 years (range 12-75). The patients shown to have an aneurysm were older

Table 227 patients with IIIrd nerve palsy without subarachnoid haemorrhage

\begin{tabular}{|c|c|}
\hline Dynamic CT & Angiography \\
\hline $\begin{array}{l}\text { Ipsilateral Carotid } \\
6 \text { PCA aneurysms predicted } \\
1 \text { PCA aneurysm and ophthalmic artery aneurysm predicted } \\
3 \text { aneurysms suspected } \\
1 \text { loop of PCA predicted } \\
16 \text { predicted normal }\end{array}$ & $\begin{array}{l}6 \text { aneurysms confirmed } \\
\text { both confirmed } \\
1 \text { infundibulum: } 2 \text { with loop of large dominant PCA } \\
\text { loop of PCA confirmed } \\
16 \text { confirmed normal }\end{array}$ \\
\hline $\begin{array}{l}\text { Contralateral Carotid } \\
24 \text { normal } \\
1 \text { aneurysm predicted } \\
1 \text { aneurysm suspected } \\
1 \text { ectasia }\end{array}$ & $\begin{array}{l}12 \text { had angiogram; } 12 \text { normal } \\
3 \text { mm PCA aneurysm confirmed } \\
\text { loop of large PCA } \\
\text { ectasia confirmed }\end{array}$ \\
\hline $\begin{array}{l}\text { Basilar System } \\
1 \text { aneurysm predicted } \\
26 \text { normal }\end{array}$ & $\begin{array}{l}\text { confirmed superior cerebellar aneurysm } \\
17 \text { had angiography; } 17 \text { normal }\end{array}$ \\
\hline
\end{tabular}

$\star \mathrm{PCA}=$ posterior communicating artery 
Figure 2 CT's on left and corresponding

angiogram on the right. (a) Normal oblique

reformation terminal

carotid (C) and large

posterior communicating

artery (arrow).

(b) Normal angiogram.

(c) Small rounded possi. aneurysm on oblique

reformatted CT (arrow,

(d) Angiogram shows it be a loop on a dominant posterior communicating artery (arrow).

(e) Oblique C

reformation showing larg aneurysm $(A)$ separate from the carotid $(C)$.

(f) Vertebral angiogram (frontal); origin of the

partly thrombosed giant aneurysm between the posterior cerebral and

superior cerebellar arteries.

(g) Oblique CT

reformation-ophthalmic artery aneurysm $(O)$ an posterior communicating artery aneurysm $(P)$. (h) Lateral angiogram confirms.

(i) Coronal CT

laterally projecting bi-

lobed aneurysm (arrow).
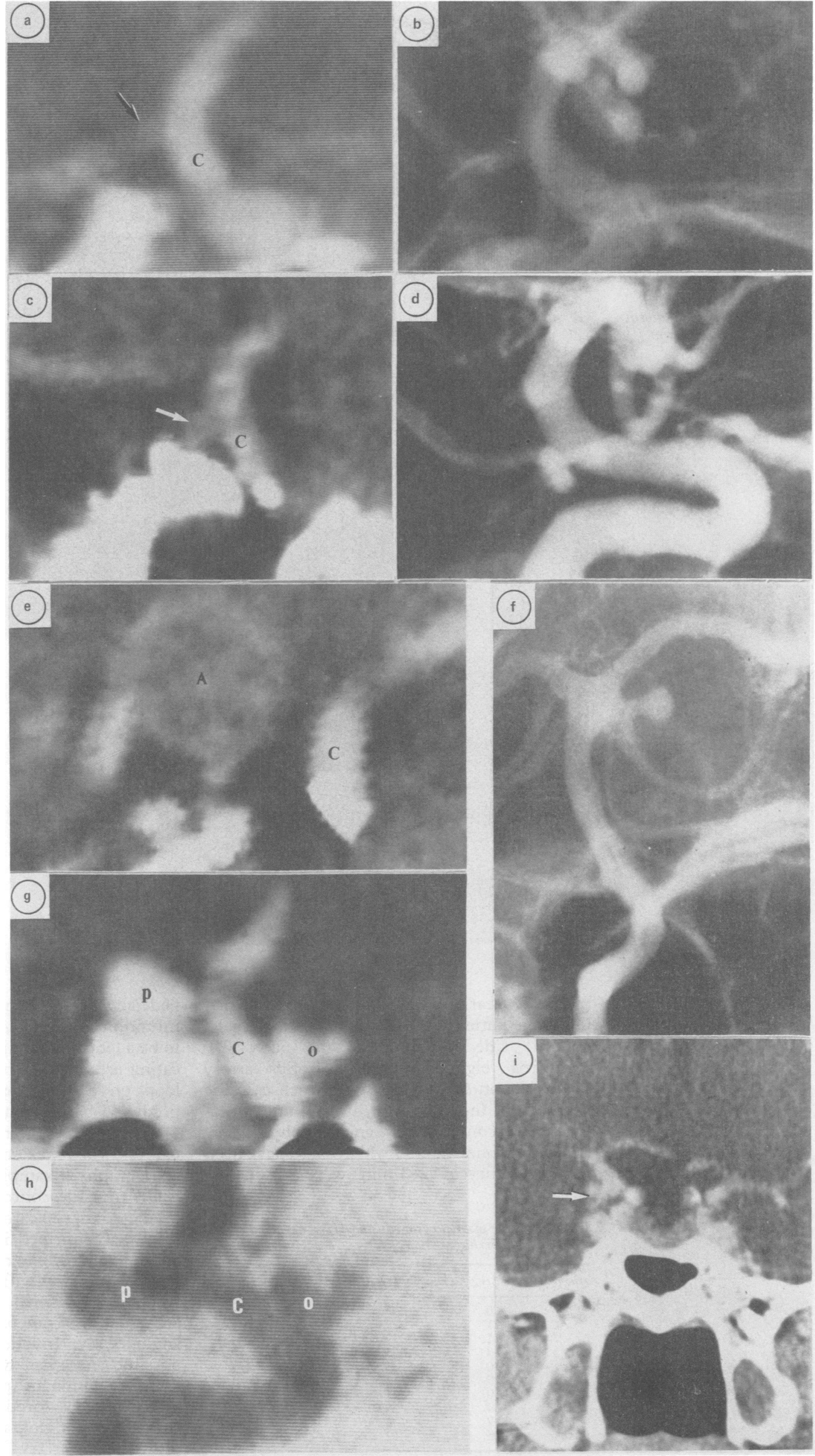
Figure 2 CT's on left and corresponding angiogram on the right. (j) Lateral angiogram confirms.

(k) Coronal CTlaterally projecting aneurysm (arrow).

(l) Lateral angiogram confirms.

(m) Axial CT-large bilobed (or 2 separate)

posterior communicating artery aneurysm. One lobe projecting laterally (arrow) and one posteriorly (arrowhead). (n) Lateral angiogram confirms 1 broadly based bi-lobed aneurysm; lateral lobe (arrow), posterior lobe (arrowhead).

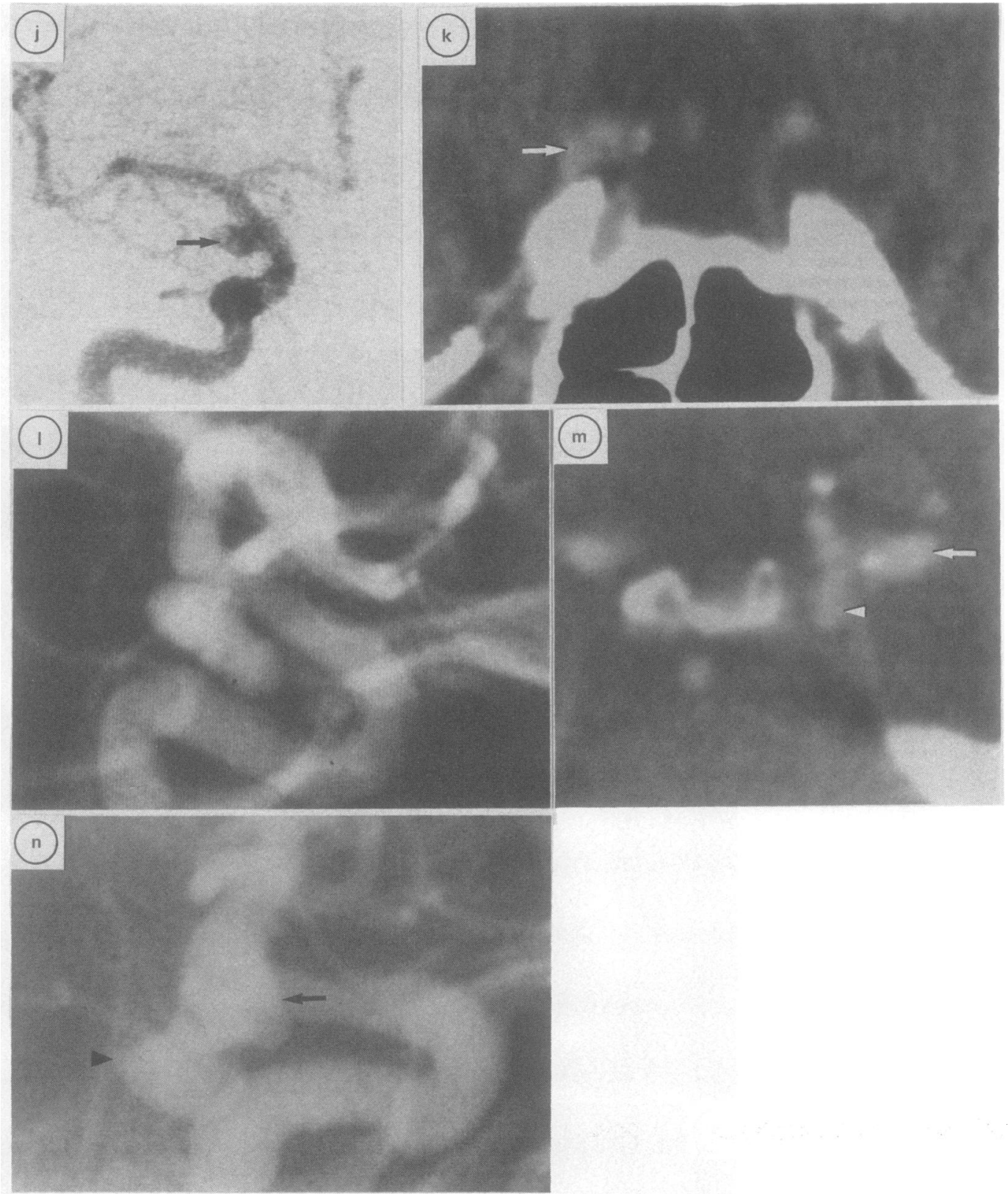

(mean 56 years) with a range of 35-75 years. Only one patient with an aneurysm was male. On the side ipsilateral to the palsy CT identified eight terminal carotid artery aneurysms in seven patients; in each case the presence of the aneurysm, its size and direction, were confirmed by angiography. Three ipsilateral abnormalities which could have been a small aneurysm $(2-3 \mathrm{~mm})$ were also identi-

Table 3 Size of aneurysm causing IIIrd nerve palsy without haemorrhage

\begin{tabular}{lccc}
\hline Aneurysm & Length $(\mathrm{mm})$ & Depth $(\mathrm{mm})$ & Width $(\mathrm{mm})$ \\
\hline PCA & $\star 10$ & 6 & 5 \\
& $\star 11$ & 5 & 7 \\
& 11 & 9 & 5 \\
& 8 & 5 & 5 \\
& 10 & 7 & 7 \\
& 15 & 12 & 12 \\
& 10 & 4 & 4 \\
& 9 & 5 & 4 \\
Basilar & 75 & 4 & 4 \\
\hline
\end{tabular}

^Patient from the retrospective review. fied; angiography showed one to be a $2 \mathrm{~mm}$ infundibulum (fig 1), and each of the other two to be a loop of a dominant posterior communicating artery (fig $2(\mathrm{~b}),(\mathrm{c})$ ). In another case a loop on a posterior communicating artery predicted by CT was confirmed at angiography. Sixteen ipsilateral vessels were normal on CT and each was confirmed to be normal at angiography. Examples are given in fig 2.

On the side contralateral to the palsy CT predicted that 23 carotids would be normal and this was confirmed in the 12 cases in whom contralateral angiography was performed. In one patient (with multiple ipsilateral aneurysms) a small aneurysm was predicted and a $3 \mathrm{~mm}$ aneurysm was confirmed at angiography. In one patient CT detected a possible aneurysm which was found to be a loop of dominant posterior communicating artery. Ectasia, predicted in one carotid was confirmed at angiography. A giant aneurysm of the basilar artery predicted by CT was confirmed to be a superior cerebellar artery 
aneurysm at angiography (fig $2(\mathrm{e}),(\mathrm{f})$ ). In the other 26 patients the basilar artery was predicted by CT to be normal, 17 had vertebral angiography and each was normal.

The sizes of the aneurysms responsible for IIIrd nerve palsy in the absence of subarachnoid haemorrhage are given in Table 3, which includes the two cases from the retrospective study. The maximum diameter was $>10 \mathrm{~mm}$ in only three, and the smallest aneurysm was 7 $\mathrm{mm}$ in maximum diameter.

Dynamic CT predicted five abnormalities at sites other than the origin of the posterior communicating artery or terminal basilar artery: a small ( $3 \mathrm{~mm}$ ) internal carotid bifurcation aneurysm, an ophthalmic artery aneurysm, (fig 2(g), (h)) an anterior communicating artery aneurysm, a temporal pole arteriovenous malformation and a large abnormal vein around the brain stem. Each of these lesions was confirmed by angiography.

\section{Discussion}

Dynamic CT scanning correctly predicted the size and site of the aneurysm responsible for the IIIrd nerve palsy in each patient whose angiogram showed an aneurysm. All vessels predicted to be normal on CT $(n=44)$ were shown to be normal by angiography. These findings indicate that dynamic CT scanning with reformation is an accurate and valuable test in patients with IIIrd nerve palsy. All aneurysms causing IIIrd nerve palsy without subarachnoid haemorrhage were $7 \mathrm{~mm}$ or greater in their largest diameter. With dynamic CT we were able to detect an abnormality as small as a $2 \mathrm{~mm}$ infundibulum and a $3 \mathrm{~mm}$ contralateral aneurysm. It is therefore unlikely that an aneurysm causing a IIIrd nerve palsy would be missed by dynamic CT. Also it is likely small abnormalities $2-3 \mathrm{~mm}$ in diameter do not represent an aneurysm responsible for a
IIIrd nerve palsy but a loop or infundibulum. The technique has further advantages: all vessels may be examined, including those of the posterior circulation, and other structural lesions responsible for a IIIrd nerve palsy will be detected.

The technique is simple to perform, and takes only a moderate amount of scanning and radiologist time; the method certainly could be incorporated into the protocols of any neuroradiology department. The risks involved are significantly less than those of angiography, the examination takes less time, can be performed on an outpatient basis and is much cheaper.

The results of this study indicate that dynamic CT scanning should be the first radiological examination undertaken in patients presenting with a partial or complete IIIrd nerve palsy in the absence of subarachnoid haemorrhage. Only the minority of patients in whom CT indicates an aneurysm or vascular anomaly need be considered for angiography.

1 Kwan E, Laucalla $M$, Hedges $T$, Wolpert S. A clinicowan $\mathrm{E}$, Laucalla $\mathrm{M}$, Hedges $\mathrm{T}$, Wolpert $\mathrm{S}$. A cliniconeuradiologic approach to third cranial nerve

2 Bartleson J, Trautmann J, Sundt T. Minimal oculomotor nerve paresis secondary to unruptured intracranial aneurysm. Arch Neurol 1986;43:1015-20.

3 Kissel J, Burde R, Klingele T, Zeiger $H$. Pupil-sparing oculomotor palsies with internal carotid-posterior communicating artery aneurysms. Ann Neurol 1983; 13:149-54.

4 O'Connor P, Tredici T, Green R. Pupillary-sparing third nerve palsy due to aneurysms: a survey of 2419 neurological surgeons. J Neurosurg 1983;58:792-3.

5 Barnes $M$, Hunt B, Williams I. The role of vertebral angiography in the investigation of third nerve palsy. J Neurol Neurosurg Psychiatry 1981;44:1153-5.

6 Keane J. Aneurysms and third nerve palsies. Ann Neurol 1983;14:696-7.

7 Soni S. Aneurysms of the posterior communicating artery and oculomotor paresis. J Neurol Neurosurg Psychiatry 1974;37:475-84.

8 Schmid U, Steiger H, Huber P. Accuracy of high resolution computed tomography in direct diagnosis of cerebral aneurysms. Neuroradiology 1987;29:152-9.

9 Vonofakos D, Hacker H, Grau H. Direct visualisation of intracranial aneurysms by multiplane dynamic CT. American Journal of Neuroradiology 1983;4:425-8. 